Article

\title{
Research on Regional Economic Innovation-driven Develop- ment and Spatial Characteristics in Sichuan Province
}

\author{
Hong Wang ${ }^{1, *}$, Ming-ning $\mathrm{Lu}^{2}$ and Za-mo $\mathrm{Er}^{3}$ \\ 1 Economic \& Management School, Xichang University, Xichang, 615013, China; giant945@126.com (H.W.); \\ 2 Economic \& Management School, Xichang University, Xichang, 615013, China; 576339482@qq.com(M. L.) ; \\ 3 Economic \& Management School, Xichang University, Xichang, 615013, China; zamo_er@163.com(Z. E.) ; \\ * Correspondence: giant945@126.com
}

\begin{abstract}
This paper uses the spatial analysis software GeoDa as a tool, takes GRP (Gross regional product) of Sichuan Province in 2012 and 2018 as the dependent variable, and takes the city (autonomous prefecture) factor-driven, investment-driven and innovation-driven indicators as the dependent variable to explore the impact of innovation activities on regional economic development and the spatial distribution characteristics of regional economy. Through the comparison of the global correlation and local correlation, this paper explores the crux of the regional economic polarization and unbalanced development, and puts forward some measures to solve the existing economic development problems, such as cultivating and improving the regional industrial dependence, accelerating the regional transportation accessibility and convenience, and constructing the regional collaborative innovation system, So as to achieve the strategic goal of the construction of innovative Province in Sichuan Province.
\end{abstract}

Keywords: Regional Economic; Innovation-driven; Development; Spatial Characteristics

\section{Introduction}

In 2012, the Chinese government launched a call to encourage Chinese scientific and technological circles to strive for innovation and provide strong scientific and technological support for building a moderately prosperous society in an all-round way. In the same year, China formally put forward the strategy of innovation driven development, emphasizing that scientific and technological innovation is the strategic support for improving social productivity and comprehensive national strength, and must be placed at the core of the overall national development. In 2016, at the China Science and Technology Innovation Conference, the 18th academician conference of the Chinese Academy of Sciences, the 13th academician conference of the Chinese Academy of engineering, and the Ninth National Congress of the China Science and technology agreement, it was once again emphasized that "to achieve the two centenary goals and realize the Chinese dream of the great rejuvenation of the Chinese nation, we must adhere to the path of independent innovation with Chinese characteristics, Facing the forefront of science and technology in the world, the main battlefield of economy and the major needs of the country, we should speed up scientific and technological innovation in various fields and grasp the opportunities of global scientific and technological competition. " On November 13, 2017, the general office of Sichuan provincial government issued the implementation plan for the construction of innovative provinces in Sichuan Province, which made it clear that by 2020, positive progress will be made in the comprehensive innovation and reform experiment, major breakthroughs will be made in the reform of science and technology system, and the whole province will enter the stage of innovation driven development, basically becoming a national innovation driven development leading province and an innovative Sichuan. Therefore, it is of great theoretical and practical significance to study the 
characteristics of regional economic innovation driven development and economic spatial distribution in Sichuan Province.

\section{Scientific connotation of innovation, innovation-driven and innovation driven de- velopment}

\subsection{The scientific meaning of innovation}

Schumpeter first put forward "innovation" in his book "the theory of economic development" from a dynamic perspective, holding that innovation is the change of production function and the recombination of existing resources [1].Oslo Manual: innovation data collection, reporting and use (4th Edition) defines innovation as a new or improved product or process (or a combination thereof), which is significantly different from the previous product or process of the unit and has been provided to potential users (products) or used by the unit (processes). According to the definition of innovation in the Oslo manual, all innovations must contain a certain degree of novelty [2]. This novelty includes: organizational innovation for enterprises, new products for markets, and new knowledge for the world. The former emphasizes the economic attribute of innovation and emphasizes the process of introducing new elements or new combinations of elements into the production system to produce value-added; The latter emphasizes the scientific nature of innovation and the scientific activities of innovation. From the field types of innovation, the common types of innovation are science and technology innovation, organization innovation, management innovation, system innovation and so on.

Innovation needs collaborative innovation of industry, education and research, not just cooperation innovation of industry, University and research. Collaborative innovation refers to the joint innovation of all parties in the same innovation platform, not just the relationship of technology transfer. Industry, University and research are not only industrial departments, universities and scientific research institutions, but also the coordination of functions between industrial development and talent training and scientific research. The link of coordinated innovation of industry, University and research is mainly in the process of scientific discovery or innovation knowledge incubation as the link of new technology [3]. There are three significant levels of scientific and technological innovation: knowledge innovation, namely scientific discovery; Technological innovation, that is, based on scientific discovery and using scientific invention to create technology; Technological innovation, which is based on scientific discovery or scientific invention, makes significant changes and improvements to the organization of production activities and process flow.

\subsection{Scientific characteristics driven by innovation}

The concept of "innovation driven" was first put forward by Porter (1990) in his book "national competitive advantage", in which he divided the development of national competitive advantage into four stages: factor driven, investment driven, innovation driven and wealth driven. Porter believes that when an economy forms a complete diamond system, and the key elements in the diamond system interact significantly, the economy realizes the innovation drive [4]. The essence of innovation driven is that in the economic development system, the allocation rules of elements, investment and other resources are carried out to achieve the goal of innovation system, so that the effect of innovation on the speed and quality of economic development is obvious.

\subsection{Innovation-driven development}

Innovation driven development refers to taking innovation as the main endogenous driving force of economic society and an important means of promoting economic and social development, promoting the transformation and upgrading of economy and entering the era of innovation economy. Innovation driven development is not independent of factor driven development or investment driven development, but an innovative 
economic model with collaborative effect of factor and investment allocation under the leading position of innovation driven development. Innovative economy, which embodies the requirements of resource conservation and environment friendliness, is an economy based on knowledge and talents, with innovation as the main driving force, with the development of new technologies and new products with independent intellectual property rights as the focus, and with innovative industries as the symbol [5].

\section{The gap between innovation driven development goals and development status}

In order to actively deal with the "neck sticking" phenomenon of key and core technologies restricting economic and social development, the Chinese government has taken the initiative to put forward specific and feasible national innovation driven development strategy. On the basis of the national innovation strategy outline, Sichuan Province also puts forward the action requirements of building innovative province.

\subsection{Strategic objectives of national innovation driven development}

In 2016, China's "national innovation driven development strategy outline" was issued, further defining the "three-step goals" of innovation driven development strategy: the first step is to enter the ranks of innovative countries by 2020, basically build a national innovation system with Chinese characteristics, and strongly support the realization of the goal of building a moderately prosperous society in an all-round way; The second step is to become one of the most innovative countries by 2030 , realize the fundamental transformation of development driving forces, and greatly improve the level of economic and social development and international competitiveness, so as to lay a solid foundation for building an economic power and a society of common prosperity; The third step is to build China into a world power of scientific and technological innovation by 2050, to become the world's major scientific center and innovation highland, and to provide strong support for China to build a prosperous, strong, democratic, civilized and harmonious modern socialist country and realize the Chinese dream of the great rejuvenation of the Chinese nation. Under the guidance of the national innovation driven strategy, Sichuan Province has successively issued provincial innovation driven development goals and policy supporting documents.

\subsection{Innovation driven goals of Sichuan Province}

In 2013, Sichuan province put forward the concept of conscious innovation, aiming at the problems of weak innovation subject capacity and regional imbalance, and issued a series of targeted new policies. In 2017, according to the requirements of the implementation plan for Sichuan innovative province construction, the main indicators of Sichuan innovative province construction are divided into ten secondary indicators and 30 third level indicators (including 26 quantitative indicators and 4 qualitative indicators). The basic indicators for Sichuan innovative province construction are 2015 data and the target index is 2020 data[6] . So far, there is a clear gap between other cities (Autonomous prefectures) and the target, except Chengdu. What causes this dilemma to appear? This paper attempts to use the spatial econometric analysis method to explore the main reasons for the failure of Sichuan innovative province construction plan to be fully realized.

\section{The relationship between innovation driven kinetic energy and economic develop- ment of Sichuan Province}

From the perspective of geographical location, Sichuan Province is located in Southwest China, covering an area of 486000 square kilometers. It borders Chongqing and Yunnan, Guizhou, Qinghai, Gansu and Shaanxi provinces. It is the gateway between central provinces and Western China, and also the core of western development. Sichuan Province is a large province in the West and a multi-ethnic province. It has 18 cities and three minority autonomous prefectures, Aba Tibetan and Qiang Autonomous prefecture, Ganzi Tibetan Autonomous prefecture and Liangshan Yi Autonomous prefecture. From the 
perspective of China's economic development, since 2010, Sichuan Province has ranked eighth in the national GRP for four consecutive years, and since 2015, Sichuan Province has ranked sixth in the GRP for five consecutive years. The overall development of Sichuan Province ranks first, but there is still a significant gap compared with Guangdong Province, which ranks first in China. From 2012 to 2019, the average annual growth rate of GRP in Sichuan Province is about $9.43 \%$, and there is still a big gap between the growth rate of GRP in Sichuan Province and that of Guangdong Province (11.08\%).

From the perspective of the economic composition of Sichuan Province, the gross regional product (GRP) of Sichuan Province in 2012(GRP_2012 ) is selected and GRP in 2018 (GRP_2018) as a comparison. Figure 1 shows that the economic development of Sichuan Province is unbalanced and inadequate. From the overall economic performance of the province, Chengdu City single pole breakthrough and the province's "Stronger the Southeast, weaker the Northwest " situation. This spatial distribution pattern is the economic "short board" which restricts the high quality and speed improvement of Sichuan Province. Compared with Chengdu, the first in the province, and Ganzi Autonomous prefecture, the last ranked City, the former is about 49 times higher than that of the latter, and the economic polarization in the province is extremely significant.

According to the GRP of each city (autonomous prefecture) in 2012, the 21 cities (autonomous prefectures) in the province are divided into five grades according to 1.5 times of the quartile difference between the upper and lower boundaries (Hinge = 1.5); More than $75 \%$ of the regions include Deyang City, Mianyang City, Nanchong City and Yibin City, which are located in the second echelon of the province. However, compared with the first echelon, there is a big gap in GRP; $50 \%$ to $75 \%$ of the areas include Dazhou City, Ziyang City, Neijiang City, Luzhou City, Leshan City and Liangshan Yi Autonomous prefecture, which are in the third echelon of the province, slightly inferior to the second echelon; The 25\% to 50\% range includes Guang'an City, Suining City, Meishan City, Zigong City and Panzhihua City, which is in the fourth echelon of the province, obviously behind the second and third echelons; Less than $25 \%$ of the regions include Ganzi, Aba, Guangyuan, Bazhong and Ya'an, which are in the fifth echelon of the province and significantly behind the second, third and fourth echelons. It can be seen that in addition to the obvious polarization of economic development in Sichuan Province, the problem of unbalanced and insufficient regional economic development is also very prominent.

In 2018, Chengdu's regional economic development is still far ahead and further widens the gap with other cities (autonomous prefectures), while Ganzi, Aba, Bazhong, Guangyuan and Ya'an continue to be at the bottom of the province. In the six-year development process, Chengdu has always been in the leading position and further widened the gap; Ganzi Autonomous prefecture, Aba Autonomous prefecture, Bazhong City, Guangyuan City and Ya'an City, which are at the bottom of economic development, are also developing slowly; Only Ziyang City's regional economic growth slowed down significantly (the average annual growth rate was only $1.38 \%$ ), while Zigong City's regional economic growth was the most significant, with an average annual growth rate of $9.83 \%$. 


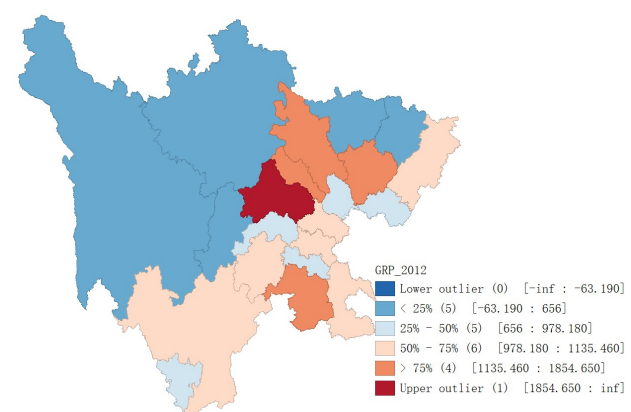

(a)

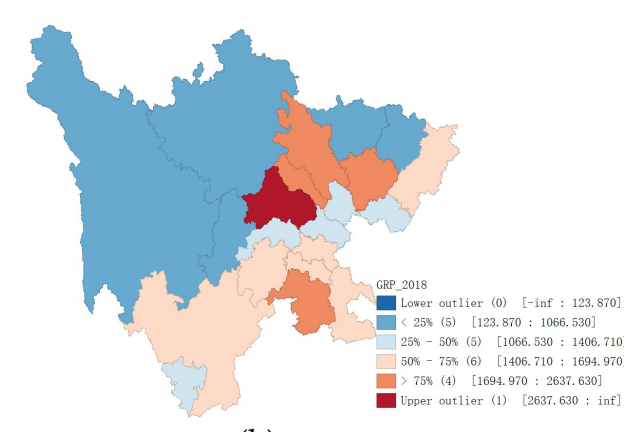

(b)

Figure 1. Box maps ( Hinge =1.5) of GRP of Sichuan Province in China, and: (a) Box map of GRP in 2012; (b) Box map of GRP in 2018.

The accessibility and convenience of transportation in a region are mainly reflected in the distribution and use efficiency of high-grade highways, high-speed railways and airports. The convenience of transportation not only reflects the intensity of regional basic investment and business supporting environment, but also an important support for regional economic development. This paper selects the highway passenger transport turnover of Sichuan Province in 2012 (Pas_2012) and road freight turnover (Fre_H_2012) and highway passenger traffic turnover $\left(\mathrm{Pk}_{2018)}\right.$ and highway freight turnover in 2018 (Fre_k_2018) four sets of data are used to represent investment driven, and the spatial characteristics of traffic convenience and its relationship with economic development are discussed, as shown in Figure 2.

It can be seen from Figure 2a that in 2012, Chengdu had the largest turnover of highway passenger transport, Guang'an City, Guangyuan City, Zigong City, Ya'an City and Panzhihua City had the lowest turnover of highway passenger transport in the whole province, and Nanchong City, Neijiang City, Luzhou City and Liangshan Autonomous prefecture had the middle turnover of highway passenger transport. As can be seen from Figure 2b, in 2012, the highway freight volume of Chengdu, Leshan and Dazhou ranked the top three in the province, the highway freight turnover of Deyang and Luzhou ranked the second in the province, and the highway freight turnover of Ganzi and Bazhong was the lowest in the province. As can be seen from Figure 2c, in 2018, Chengdu had the largest turnover of highway passenger transport, followed by Nanchong, Neijiang, Luzhou and Liangshan, and Guangyuan, Guang'an, Zigong, Ya'an and Panzhihua ranked in the top five of the province. As can be seen from Figure 2d, in 2018, Chengdu still ranked first in the province in terms of road freight turnover, followed by Dazhou, Luzhou, Leshan and Liangshan, and Ganzi, Ziyang, Zigong, Guangyuan and Guang'an in terms of freight turnover. In short, the higher the accessibility and convenience of transportation, the higher the level of economic development, and the more balanced the regional economic development.

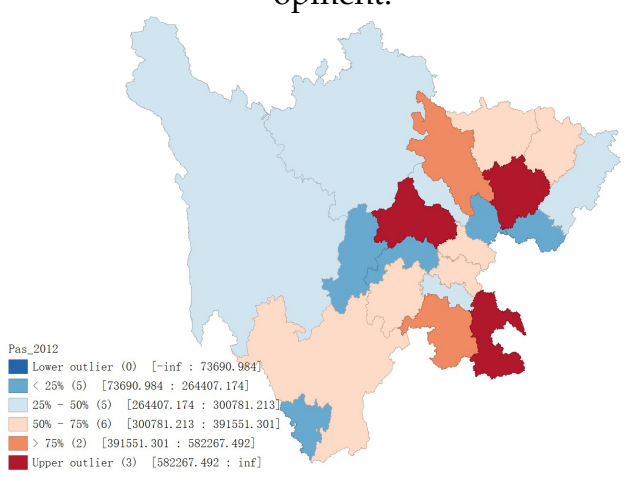

(a)

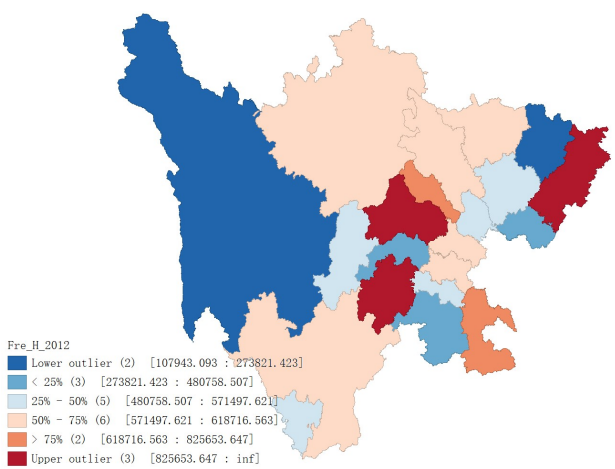

(b) 


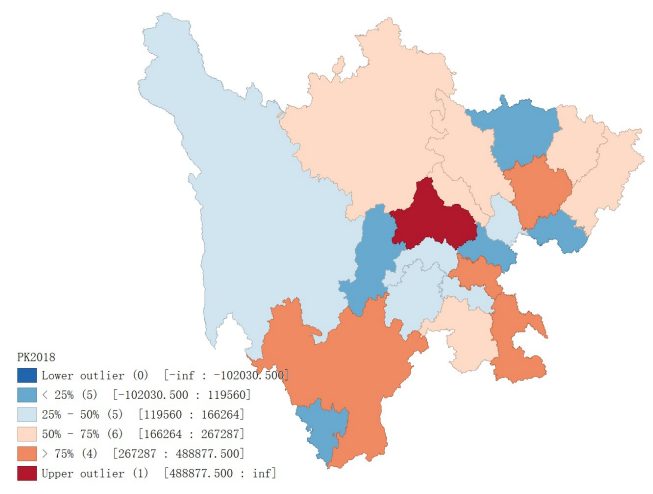

(c)

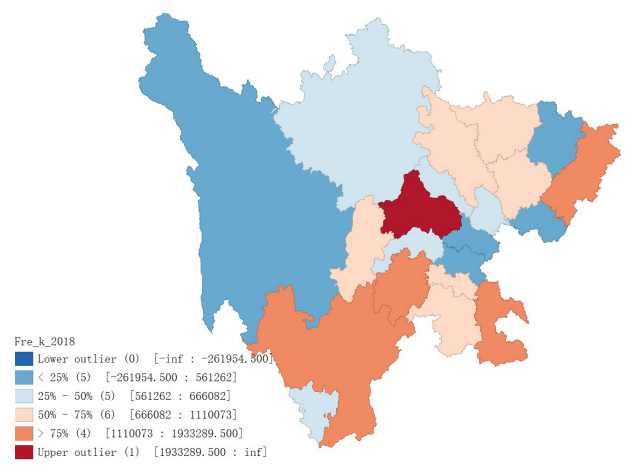

(d)

Figure 2. Box maps ( Hinge=1.5) of passenger \& freight transport turnover of Sichuan Province in China, and: (a) Highway passenger transport turnover in 2012; (b) Highway freight transport turnover in 2012; (c) Highway passenger transport turnover in 2018; (d) Highway freight transport turnover in 2018.

The innovation level of a region can be reflected by many quantitative indicators related to culture, education, scientific research and knowledge achievements. The internal expenditure data of research and development funds is one of the important representative parameters that directly reflect the intensity of scientific research investment in a region. This paper selects the internal expenditure of R\&D of each city (autonomous prefecture) in 2012 (IEoR\&_2012) and the internal expenditure of R\&D of each city (autonomous prefecture) in 2018 (IEoR\&_2018), as shown in Figure 3. As can be seen from Figure 3a, in 2012, the scientific research investment level of Chengdu, Deyang, Mianyang and Yibin was at the leading level in the province, followed by Panzhihua, while the scientific research investment level of Ganzi, Aba, Liangshan, Bazhong and Guang'an was at the lowest level in the province. As can be seen from Figure 3b, in 2018, the scientific research investment of Chengdu, Deyang and Mianyang cities moved to the top three of the province, the scientific research investment of Leshan and Yibin cities was in the second level in the province, while the scientific research investment of Ganzi, Aba, Bazhong, Guangyuan and Ziyang cities was at the bottom of the province. Compared with figure 1a and figure 3a, in 2012, the positive correlation between Chengdu's scientific research investment and its GRP is obvious, that is, the greater the intensity of scientific research investment, the faster the economic development. However, compared with Chengdu, the positive effect of scientific research investment in Deyang and Mianyang on regional economy is worse. In 2012, the intensity of scientific research investment in Ganzi, ABA and Bazhong was the lowest in the whole province, and the three were also at the bottom of the GRP. It can be seen that there is a positive correlation between scientific research investment and the GRP of regional economic development. However, there are some exceptions. For example, in 2012, the scientific research input of Liangshan Autonomous prefecture is also the lowest level in the province, but its corresponding GRP has no obvious impact, and the correlation is not obvious. Comparing the scientific research input with the GRP in 2018, the law is similar to that in 2012. It can be seen that the effect of innovation driven is related to innovation intensity, but it is also restricted by other factors. The impact of scientific research investment on regional economic development depends on the intensity of scientific research investment, the direction of innovation development and the principle of resource allocation around innovation. If the relationship between the three is unreasonable, there will be a certain degree of uncertainty between innovation drive and regional economic development results. 


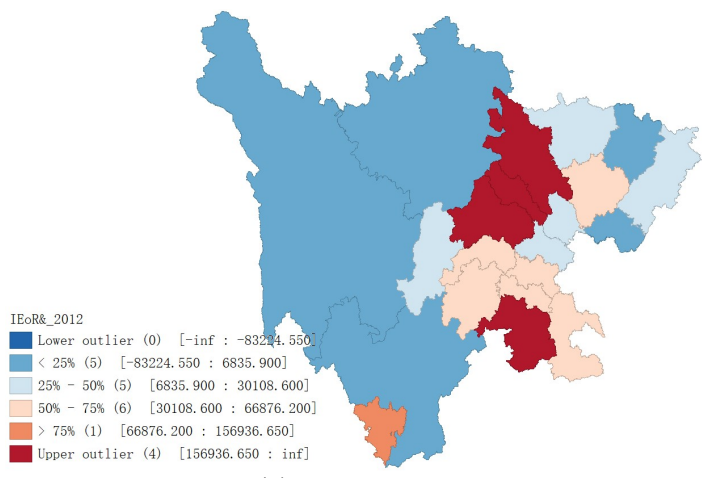

(a)

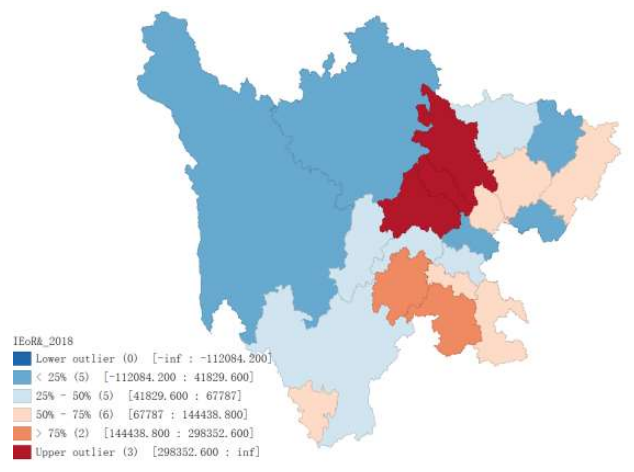

(b)

Figure 3. Box maps (Hinge=1.5) of R\&D internal expenditure of Sichuan, China, and: (a) Box map of R\&D Internal expenditure in 2012; (b) Box map of R\&D Internal expenditure in 2018.

Through the above single factor study, it is found that the phenomenon of serious polarization of regional economic development and unbalanced regional development in Sichuan Province is clear at a glance. Only by further improving the development level and quality of the backward areas in Sichuan Province and solving the development problems of the backward areas in Sichuan Province, can the "short board" of economic development in Sichuan Province be made up. Through the above analysis, the driving effect of innovation on regional economic development is quite different. Innovation has a significant economic driving effect on Chengdu, and it also has a positive effect on Deyang City and Mianyang City in the southeast of Chengdu, but it has no significant effect on the economic development of other regions. Obviously, whether the innovation of each city (autonomous prefecture) can effectively drive the high-speed and high-quality development of local economy is also affected by other conditions.

In order to more comprehensively analyze the overall characteristics of regional economic development in Sichuan Province, this paper will further study the interaction between multiple factors of economic development in various regions of Sichuan Province. Global autocorrelation analysis mainly explores the spatial association and difference of an attribute in a region, which is usually reflected by global Moran's I and gear index G; Local autocorrelation analysis can explore the variability of local space, which is generally measured by Moran scatter diagram and local index (LISA). This is exploratory spatial data analysis (ESDA). The commonly used tools include geoda and ArcGIS software [7].

\section{Analysis on spatial distribution characteristics of multiple factors of regional econ- omy in Sichuan Province}

There are many factors that affect the speed and quality of regional economic development. The single effect of economic development factors and the joint action between the main factors sometimes have different comprehensive effects due to the mutual influence. At the same time, considering the economic development of a region, it is often closely related to its adjacent areas. This part will consider the spatial weight relationship between the cities and autonomous prefectures when studying the spatial distribution characteristics of the regional economy.

\subsection{Setting of spatial weight matrix among cities and autonomous prefectures}

According to the first law of geography, "all attribute values on a geographic surface are related to each other, but closer values are more strongly related than are more distant ones ." this kind of spatial attribute feature is usually represented by spatial weight matrix. The spatial weight matrix can be divided into contiguity matrix and distance matrix. In this paper, the spatial weight matrix $\mathrm{W}$ adopts the contiguity matrix, which is used to reflect the mutual dependence between individual units in space. Wij is the element of the matrix, which represents the contiguity relationship between individual unit I and 
individual unit J. if it is adjacent, Wij is 1 , otherwise it is 0 . The contiguity between an individual cell and its adjacent cell is called first-order contiguity, and the contiguity between an individual cell and its adjacent cell is called second-order contiguity. According to the connection relationship, we can construct the following spatial weight matrix $\mathrm{w}$ to reflect the contiguity relationship between the research objects.

$$
W=\left(\begin{array}{ccc}
w_{11} & \ldots & w_{1 n} \\
\vdots & \ddots & \vdots \\
w_{n 1} & \cdots & w_{n n}
\end{array}\right)
$$

Among

$$
w_{i j}=\left\{\begin{array}{l}
1 \\
0
\end{array}\right.
$$

When city (autonomous prefecture) I is adjacent to city (autonomous prefecture) J; When city (autonomous prefecture) I is not adjacent to city (autonomous prefecture) $\mathrm{J}$.

There are three methods to create spatial weight matrix: rook criterion, bishop criterion and queen criterion. Rook criterion indicates that there is a common edge relationship between adjacent cells, which is called contiguity relationship. Bishop criterion indicates that there is a common point between adjacent cells, which is called contiguity relationship. While queen criterion indicates that there is a common point or a common edge relationship between adjacent cells, which is called contiguity relationship. Therefore, Queen criterion includes rook criterion or bishop criterion. This paper uses the queen criterion to set the first-order adjacent spatial weight matrix of each city (autonomous prefecture) in Sichuan Province. Generally, the spatial weight matrix generated by GeoDa software is a sparse matrix stored in text format. See Table 1 for details.

\begin{tabular}{|c|c|c|c|c|c|c|c|}
\hline \multirow{2}{*}{$\begin{array}{l}\text { Region } \\
\text { Chengdu }\end{array}$} & \multirow{2}{*}{$\begin{array}{l}\text { Number of } \\
\text { Neighbors }\end{array}$} & \multicolumn{6}{|c|}{ Neighbors' Name } \\
\hline & & 5 Deyang & Meishan & Ya'an & Ziyang & $\mathrm{Aba}$ & \\
\hline Zigong & & 5 Luzhou & Neijiang & Leshan & Meishan & Yibin & \\
\hline Panzhihua & & 1 Liangshan & & & & & \\
\hline Luzhou & & 3 Zigong & Neijiang & Yibin & & & \\
\hline Deyang & & 5 Chengdu & Mianyang & Suining & Ziyang & $\mathrm{Aba}$ & \\
\hline Mianyang & & 5 Deyang & Guangyuan & Suining & Nanchong & $\mathrm{Aba}$ & \\
\hline Guangyuan & & 3 Mianyang & Nanchong & Bazhong & & & \\
\hline Suining & & 5 Deyang & Mianyang & Nanchong & Guangan & Ziyang & \\
\hline Neijiang & & 4 Zigong & Luzhou & Meishan & Ziyang & & \\
\hline Leshan & & 5 Zigong & Meishan & Yibin & Ya'an & Liangshan & \\
\hline Nanchong & & 6 Mianyang & Guangyuan & Suining & Guangan & Dazhou & Bazhong \\
\hline Meishan & & 6 Chengdu & Zigong & Neijiang & Leshan & Ya'an & Ziyang \\
\hline Yibin & & 4 Zigong & Luzhou & Leshan & Liangshan & & \\
\hline Guangyuan & & 3 Suining & Nanchong & Dazhou & & & \\
\hline Dazhou & & 3 Nanchong & Guangan & Bazhong & & & \\
\hline Ya'an & & 6 Chengdu & Leshan & Meishan & $\mathrm{Aba}$ & Ganzi & Liangshan \\
\hline Bazhong & & 3 Nanchong & Guangyuan & Dazhou & & & \\
\hline Ziyang & & 5 Deyang & Meishan & Chengdu & Neijiang & Suining & \\
\hline $\mathrm{Aba}$ & & 5 Chengdu & Deyang & Mianyang & Ya'an & Ganzi & \\
\hline Ganzi & & $3 \mathrm{Aba}$ & Liangshan & Ya'an & & & \\
\hline Liangshan & & 5 Panzhihua & Leshan & Yibin & Ya'an & Ganzi & \\
\hline
\end{tabular}

Table 1. Spatial Weights Matrix of Sichuan 
In addition to the above data, this paper also selected other major economic development data in 2012, such as Per Capita Gross Regional Product by Region (P_GRP_2012), Energy Consumption Index of Gross Domestic Product per Unit Area by Region (ECI_2012), Internal Expenditure on R\&D ( IEoR\&_2012), Institutions of Natural Sciences and Technology (Insti_2012), Number of Researchers in Natural Science and Technology (STP_P_2012), Scientific Research Institutions in the Field of Social Humanities and Technology (Ins_S_2012), the Number of Scientific Research in the Field of Social Humanities and Technology (SSH_P_2012), Natural Science Expenditure of Research and Development Institutions and Information and Literature Institutions of Government Departments above County Level (STE_N_2012) and the Expenditure on Humanities and Social Sciences of research and development institutions and information and Literature Institutions of government departments above county level (STE_S_2012). For comparison, select the corresponding indicators in 2018, such as Per Capita Gross Regional Product by Region (P_GRP_2018), Energy Consumption Index of Gross Domestic Product per Unit Area by Region (ECI_2018), Internal Expenditure on R \& D ( IEoR\&_2018), Institutions of Natural Sciences and Technology (Insti_2018), Number of Researchers in Natural Science and Technology (STP_P_2018), Scientific Research Institutions in the Field of Social Humanities and Technology (Ins_S_ 018), the Number of Scientific Research in the Field of Social Humanities and Technology (SSH_P_2018), Natural Science Expenditure of Research and Development Institutions and Information and Literature Institutions of Government Departments above County Level (STE_N_2018) and the Expenditure on $\mathrm{Hu}$ manities and Social Sciences of research and development institutions and information and Literature Institutions of government departments above county level (STE_S_2018). All data are sorted out by the author according to Sichuan statistical yearbook, as shown in Table 2.

The data in Table 2 can be divided into four categories. The first category is the economic development achievement index represented by per capita GRP, which is the dependent variable, and the other three categories are the independent variables; The second is represented by the energy consumption index per unit of GRP, which is a representative parameter to measure the factor input in economic development; The third type is represented by highway passenger transport turnover and freight transport turnover, which are used to measure the role of investment factors in economic development; The fourth category includes the internal expenditure of $R \& D$ funds, the number of research institutions in the field of natural science and technology, the number of research institutions in the field of social science and technology, and the internal expenditure of research funds, which are used as the influencing factors to measure the role of innovation factors in regional economic development. Using GeoDa software as a tool, this paper analyzes the overall Moran'I of each city (autonomous prefecture) in 2012 and 2018. This part will further study the interaction between the main factors of economic development in Sichuan Province Based on the spatial autocorrelation analysis of multiple variables. Next, we will analyze the spatial correlation between GRP per capita and other factors in 2012 and 2018. 
Table 2. Basic Data of Sichuan Province

\begin{tabular}{|c|c|c|c|c|c|c|c|c|c|c|c|c|}
\hline \multirow{2}{*}{$\begin{array}{l}\text { Region } \\
\text { CN_NAME }\end{array}$} & \multicolumn{2}{|c|}{ Gross Regibnal Product } & \multicolumn{2}{|c|}{ Pet Capital Gross Regional Product } & \multicolumn{2}{|c|}{ Internal Espendicure on RaD } & \multicolumn{2}{|c|}{ Institutions } & \multicolumn{2}{|c|}{ S\& T Personnel } & \multicolumn{2}{|c|}{ SeH Institutions } \\
\hline & GRP_2012 & GRP_2018 & P_GRP_2012 & P_GRP_2018 & IEOR\&_2012 & IEOR\&_2018 & Insti_2012 & Ir_NS_2018 & STP_P_2012 & STP_P_2018 & Ins_S_2012 & Ins_S_2018 \\
\hline Chengdu & 8138.94 & 15342.77 & 57624 & 94782 & 1701970 & 3923101.3 & 59 & 51 & 6601 & 7448 & 12 & $\overline{12}$ \\
\hline Zigong & 884.8 & 1406.71 & 32787 & 48329 & 55336.7 & 109505.7 & 6 & 3 & 208 & 249 & 1 & 1 \\
\hline Parzzhintua & 740.03 & 1173.52 & 60391 & 94938 & 73402.8 & 144438.8 & 4 & 3 & 219 & 136 & & \\
\hline Luzhou & 1030.45 & 1694.97 & 24317 & 39230 & 42128.9 & 122896.1 & 2 & 2 & 123 & 37 & & \\
\hline Deyang & 12802 & 2213.87 & 35945 & 62569 & 372204.5 & 572635.8 & & 1 & & 112 & 1 & 1 \\
\hline Miatyang & 1346.42 & 2303.82 & 29080 & 47538 & 830845 & 1523706.2 & 2 & 1 & 113 & 110 & & \\
\hline Guangyuan & 468.66 & 801.85 & 18672 & 30105 & 6835.9 & 41829.6 & 4 & 4 & 126 & 38 & & \\
\hline Suining & 656 & 1221.39 & 20099 & 37943 & 18145.8 & 860181.8 & 1 & & 7 & & & \\
\hline Neijiatig & 978.18 & 1411.75 & 26341 & 37885 & 66876.2 & 57640.6 & 3 & 2 & 289 & 240 & & \\
\hline Leshann & 1037.75 & 1615.09 & 31942 & 49397 & 40824.4 & 150290 & 2 & 2 & 51 & 60 & & \\
\hline Nanchong & 1180.36 & 2006.03 & 18757 & 31203 & 30108.6 & 103587.7 & 5 & 4 & 275 & 286 & & \\
\hline Meishatr & 775.22 & 1256.02 & 26168 & 42157 & 38953.3 & 50898.2 & & & & & & \\
\hline Yibing & 1242.76 & 2026.37 & 27865 & 44604 & 167088.1 & 244449.5 & 5 & 6 & 178 & 213 & & \\
\hline Guangan & 752.22 & 1250.24 & 23410 & 38520 & 3196.8 & 15196 & & & & & 1 & 1 \\
\hline Dazhou & 1135.46 & 1690.17 & 20685 & 29627 & 9387.7 & 67787 & 3 & 3 & 88 & 112 & 1 & 1 \\
\hline$Y_{a}^{\prime}$ an & 398.05 & 646.1 & 26157 & 41985 & 26498.2 & 63377.8 & 1 & 1 & 34 & 20 & & \\
\hline Bazhong & 372.4 & 645.88 & 11278 & 19458 & 3985.5 & 17287.9 & 1 & & 6 & & & \\
\hline Ziyang & 984.72 & 1066.53 & 27283 & 42112 & 13475.3 & 19236.2 & 2 & 1 & 77 & 65 & & \\
\hline Aba & 203.74 & 306.67 & 22525 & 32552 & 3454.3 & 9914.5 & 2 & 5 & 167 & 152 & 1 & 2 \\
\hline Ganzi & 175.02 & 2912 & 15753 & 24446 & 2052.4 & 3656.8 & 4 & 4 & 159 & 155 & & \\
\hline Liangshan & 1122.67 & 1533.19 & 24668 & 31472 & 1818.2 & 43295.7 & 4 & 3 & 198 & 173 & 1 & 1 \\
\hline
\end{tabular}

Table 2. Basic Data of Sichuan Province( Continued)

Tab. 2 Basic Data of Sichuarl Provinc ( Continted)

\begin{tabular}{|c|c|c|c|c|c|c|c|c|c|c|c|c|}
\hline \multirow{2}{*}{$\begin{array}{l}\text { Region } \\
\text { CN_NAME }\end{array}$} & \multicolumn{2}{|c|}{$\begin{array}{l}\text { Social Sciences and Hunanities } \\
\text { Personnel }\end{array}$} & \multicolumn{2}{|c|}{ Scientific-Techurical Experdittures } & \multicolumn{2}{|c|}{ SSH Scientific-Techurical Expenditures } & \multicolumn{2}{|c|}{$\begin{array}{l}\text { Passeriget-Killometers of } \\
\text { Highway }\end{array}$} & \multicolumn{2}{|c|}{ Freight } & \multicolumn{2}{|c|}{ Enetgy Constumption Iridex of GRP } \\
\hline & SSH_P_2012 & SSH_P_2018 & STE_N_2012 & STE_N_2018 & STE_S_2012 & STE_S_2018 & Pas_2012 & PK2018 & Fte_H_2012 & Fre_k_2018 & ECI_2012 & EC_2018 \\
\hline Chengdu & 766 & 932 & 2596977 & 3815088 & 148304 & 352657 & 3119239 & 885490 & 2367463.799 & 2840229 & 92.8 & 94.21 \\
\hline Zigong & 31 & 28 & 33327 & 69951 & 8243 & 5158 & 268360.568 & 119560 & 513997.054 & 666082 & 92.68 & 94.5 \\
\hline Parzziultua & & & 58927 & 52278 & & & 135266.999 & 59718 & 568533.02 & 622082 & 95 & 92.56 \\
\hline Luzhou & & & 26401 & 5505 & & & 884122.258 & 353549 & 644764.077 & 1528217 & 93.76 & 96.37 \\
\hline Deyang & 26 & 22 & & 81802 & 2566 & 55 & 284821.087 & 231148 & 622991.012 & 657353 & 92.9 & 95.13 \\
\hline Mianyang & & & 18707 & 48864 & & & 516301.858 & 228547 & 609243.503 & 842133 & 92.88 & 9628 \\
\hline Guangytant & & & 11186 & 7500 & & & 391551.301 & 99350 & 613412.485 & 778442 & 94.9 & 95.49 \\
\hline Stining & & & 360 & & & & 221892.554 & 126431 & 480758.507 & 561262 & 92.81 & 91.34 \\
\hline Neijiang & & & 21411 & 58031 & & & 335708.5 & 406637 & 571497.621 & 423368 & 93.53 & 96.91 \\
\hline Leshan & & & 1262 & 17340 & & & 330419.46 & 149931 & 827747.452 & 1284454 & 92.7 & 95.62 \\
\hline Nanchong & & & 51708 & 78816 & & & 604013.671 & 305224 & 508448.442 & 1110073 & 95.28 & 94.06 \\
\hline Meishatr & & & & & & & 231861.359 & 127382 & 476624.148 & 652635 & 93.42 & 94.72 \\
\hline Yibing & & & 44829 & 66636 & & & 520677.405 & 182061 & 377278.489 & 680288 & 97.46 & 96.9 \\
\hline Guangan & 12 & 12 & & & 2926 & 1277 & 235214.641 & 94478 & 328092.311 & 304937 & 92.81 & 96.52 \\
\hline Dazhou & 21 & 25 & 12102 & 25104 & 1260 & 6490 & 296296.493 & 267287 & 1117612.772 & $14421 \% 0$ & 92.9 & 95.69 \\
\hline$Y a^{\prime}$ an & & & 1668 & 1186 & & & 105575.075 & 64991 & 505142.372 & 749925 & 93.38 & 97.78 \\
\hline Bazhong & & & 450 & & & & 300781.213 & 171587 & 222928.068 & 474178 & 97.53 & 97.46 \\
\hline Ziyang & & & 18954 & 7393 & & & 374015.896 & 118469 & 575466.9 & 388922 & 92.81 & 95.88 \\
\hline $\mathrm{Aba}$ & 16 & 28 & 18323 & 58574 & 470 & 7998 & 291470.992 & 166264 & 593254.818 & 617663 & 96.02 & 93.84 \\
\hline Ganzi & & & 27857 & 44483 & & & 264407.174 & 154386 & 107943.093 & 223945 & 97.58 & 96.31 \\
\hline Liangshan & 30 & 24 & 27716 & 40146 & 4462 & 11437 & 335119.652 & 348936 & 618716.563 & 1301143 & 93.33 & 100.18 \\
\hline
\end{tabular}

Note: the blank values in Table 2 are all zero.

4.3 Overall economic distribution characteristics of cities (autonomous prefectures) in Sichuan Province 
Spatial autocorrelation analysis is a common method to study the characteristics of economic distribution. Spatial autocorrelation is also derived from the concept of correlation in univariate statistical analysis, which refers to the similarity or correlation of a thing in a certain space and its adjacent space [8]. Spatial autocorrelation analysis is to analyze the correlation between the same attributes of variables. It is to test whether the attribute value of a feature is associated with the attribute value of its adjacent spatial features. The calculation of Moran' I index can not directly determine its spatial correlation according to the positive and negative of its value, but also needs hypothesis testing. The relationship among $\mathrm{p}$ value, $\mathrm{Z}$ value, confidence and significance level in hypothesis test is shown in Table 3.

Table 3. the Relationship of P-value, Z-Value and Confidence Interval

\begin{tabular}{cccc}
\hline P value & $Z$ value & Confidence Level & Significance Level \\
\hline $\mathrm{P}<0.10$ & $\mathrm{Z}>1.65$ or $\mathrm{Z}<-1.65$ & 0.9 & Significant \\
$\mathrm{P}<0.05$ & $\mathrm{Z}>1.96$ or $\mathrm{Z}<-1.96$ & 0.95 & Very Significant \\
$\mathrm{P}<0.01$ & $\mathrm{Z}>2.58$ or $\mathrm{Z}<-2.58$ & 0.99 & Extremely Significant \\
\hline
\end{tabular}

Choosing the per capita GRP in 2012 as the first variable and the energy consumption index per unit GRP in 2012 as the second variable, the bivariate global Moran' I index is 0.142, and the bivariate spatial correlation results are shown in Figure 4 . The Monte Carlo test corresponding to Moran' I index in Figure 4 is shown in Figure 5, P=0.091. The hypothesis test is significant, showing the characteristics of spatial negative correlation, that is, if the energy consumption per unit of GRP decreases, the regional economy will grow significantly.

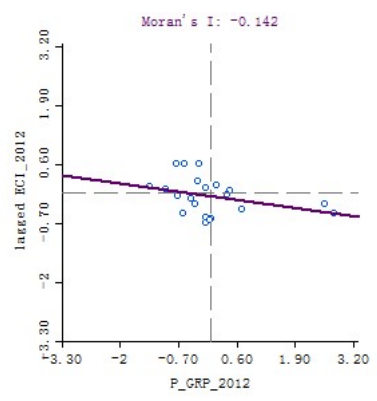

Figure 4. Bivariate Moran' I of GRP per capita and energy consumption per unit of GRP in 2012

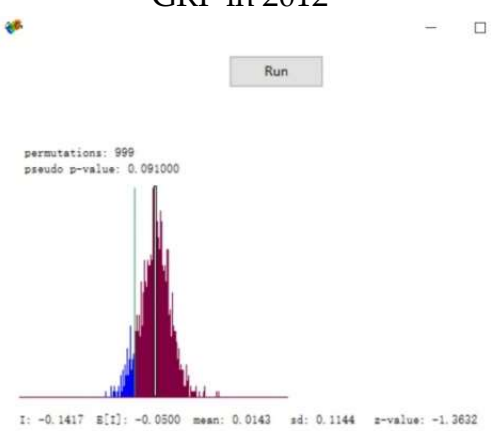

Figure 5. Hypothesis Test of Moran' I in 2012

Similarly, the GRP per capita in 2012 is selected as the first variable, followed by the highway freight turnover, highway passenger transport turnover, R\&D internal expenditure, the number of scientific research institutions in the field of Humanities and social sciences technology, the number of scientific researchers in the field of Humanities and social sciences technology, the number of scientific and technological expenditure in the field of Humanities and social sciences technology, the number of scientific research institutions in the field of natural science and technology The number of scientific researchers in the field of natural science and technology and the expenditure on science and 
technology in the field of natural science and technology are the second variables, and the bivariate global Moran' I index obtained in turn is shown in Table 4 . The variables selected in Table 4 are not significant, which reflects that in the regional economic structure of Sichuan Province in 2012, the industrial correlation degree is not obvious, and the industrial advantage is not obvious.

Table 4. Bivariate Moran' I in 2012

\begin{tabular}{|c|c|c|c|c|c|c|c|c|c|}
\hline \multirow{2}{*}{$\begin{array}{l}\text { First Variable } \\
\qquad \text { P_GRP_2012 }\end{array}$} & \multicolumn{9}{|c|}{ Second Variable } \\
\hline & Fre_H_2012 & Pas_2012 & IEoR\&_2012 & Ins_S_2012 & SSH_P_2012 & STE_S_2012 & Insti_2012 & STP_P_2012 & STE_N_2012 \\
\hline Moran'I & 0.014 & -0.027 & -0.035 & 0.036 & 0.02 & 0.015 & -0.005 & 0.001 & 0 \\
\hline PValue & 0.311 & 0.483 & 0.499 & 0.221 & 0.243 & 0.259 & 0.314 & 0.299 & 0.306 \\
\hline$Z$ Value & 0.3812 & -0.0609 & -0.1191 & 0.6172 & 0.4548 & 0.4017 & 0.1982 & 0.261 & 0.2453 \\
\hline Spatial Correlation & Non-significant & Non-significant & Non-significant & Non-significant & Non-significant & Non-significant & Non-significant & Non-significant & Non-significant \\
\hline
\end{tabular}

By selecting the per capita GRP in 2018 as the first variable and the energy consumption index per unit GRP in 2018 as the second variable, the bivariate global Moran' I index is 0.247 , and the bivariate spatial correlation results are shown in Figure 6. The corresponding hypothesis test results are shown in Figure 7. At this time, the p value is 0.019, and the $Z$ value is 2.014. The hypothesis test is very significant, showing a strong positive correlation, that is, the higher the energy consumption level of unit GRP, the faster the regional economic growth.

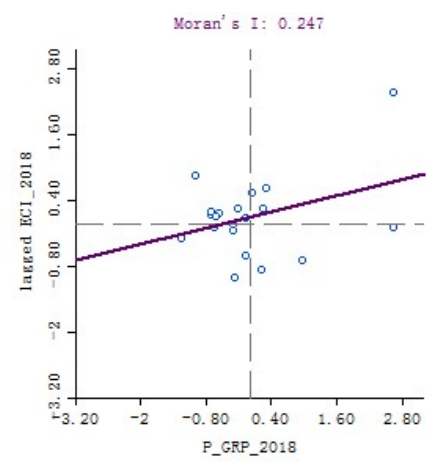

Figure 6. Bivariate Moran' I of GRP per capita and energy consumption per unit of GRP in 2018

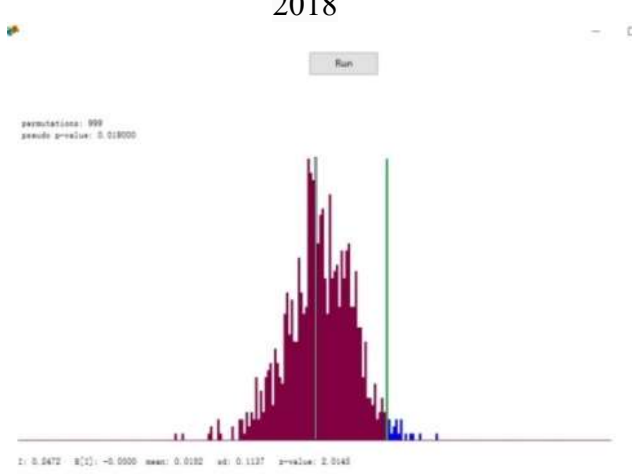

Figure 7. Hypothesis Test of Moran' I in 2018

Similarly, the GRP per capita in 2018 is chosen as the first variable, and the road freight turnover, highway passenger turnover, R\&D expenditure, scientific research institutions in the field of Humanities and Social Sciences and technology, number of scientific researchers in the field of Humanities and Social Sciences and technology, and the number of scientific research institutions in natural science and technology field are selected as the first variable The number of scientific researchers in natural science and technology and the expenditure of science and technology funds in natural science and technology are the second variables. The dual variable Moran 'I index obtained in sequence is shown in Table 5. The variables selected in Table 5 are not significant, reflecting that in the regional economic structure of Sichuan Province in 2018, the industrial relevance is also not obvious, and the industrial advantages are not obvious. 
Table 5. Bivariate Moran' I in 2018

\begin{tabular}{|c|c|c|c|c|c|c|c|c|c|}
\hline \multirow{2}{*}{$\frac{\text { First Variable }}{\text { P_GRP_2018 }}$} & \multicolumn{9}{|c|}{ Second Variable } \\
\hline & Fre_H_2018 & Pas_2018 & IEoR\&_2018 & Ins_S_2018 & SSH_P_2018 & STE_S_2018 & In_NS_2018 & STP_P_2018 & STE_N_2018 \\
\hline Non-significant & 21 & 19 & 18 & 18 & 18 & 18 & 20 & 20 & 19 \\
\hline $\mathrm{P}=0.05$ & - & 2 & 2 & 1 & 2 & 1 & 1 & 1 & 2 \\
\hline $\mathrm{P}=0.01$ & - & 0 & 1 & 1 & 0 & 1 & 0 & 0 & 0 \\
\hline $\mathrm{P}=0.001$ & - & 0 & 0 & 1 & 1 & 1 & 0 & 0 & 0 \\
\hline $\mathrm{H}-\mathrm{H}$ & - & - & Deyang & Deyang & Deyang & Deyang & Ya'an & - & - \\
\hline $\mathrm{L}-\mathrm{L}$ & - & Liangshan & Ganzi & - & - & - & - & Nanchong & Nanchong \\
\hline $\mathrm{L}-\mathrm{H}$ & - & Zigong & Aba & Ya'an & Ya'an & Ya'an & - & - & Aba \\
\hline $\mathrm{H}-\mathrm{L}$ & - & - & - & Zigong & Zigong & Zigong & - & - & - \\
\hline
\end{tabular}

From the overall point of view, through the analysis of the representative indicators of factor driven, investment-driven and innovation driven in 2012 and 2018, except for the obvious correlation between the energy consumption index of unit GRP and per capita GRP, the correlation between the other nine indicators and per capita GRP is not significant. In addition, through the above analysis, in addition to the obvious effect of innovation drive on Chengdu, it has little effect on the economic development of other regions. The above analysis proves once again that the economic development differentiation of various cities (autonomous prefectures) in Sichuan Province is particularly serious. The main reasons for this phenomenon lie in the failure to form an organic collaborative whole of innovation activities, the poor accessibility and convenience of transportation in the province, and the poor industrial correlation among regions in the province. From the perspective of global spatial analysis, scientific research talents are not only the important "bottleneck" affecting the innovation driven effect, but also the core of ensuring Sichuan Province to achieve the strategic goal of innovation province.

\subsection{Local autocorrelation analysis}

If the global spatial correlation is not significant, will there be spatial correlation in local areas? Following the previous ideas, this paper analyzes the local autocorrelation of cities (autonomous prefectures) in Sichuan Province in 2012 and 2018. Local spatial autocorrelation can reflect the similarity of the same attribute value between each region and the surrounding region, which can be used to verify the spatial heterogeneity of local region and make up for the defect of global spatial autocorrelation [9]. The same as the spatial weight matrix used in the global analysis, the local correlation between per capita GRP and energy consumption index per unit GRP in 2012 is analyzed, as shown in Figure 8. Through the bivariate Lisa significance map, it can be seen that among the 21 cities (Autonomous prefectures), 19 cities (Autonomous prefectures) are not significant, only $\mathrm{Zi}$ gong City and Meishan City have significant $(\mathrm{P}=0.05)$ correlation, and there is a "low low" clustering between the two cities, that is, the surrounding areas of low value areas are also low value. Similarly, the GRP per capita in 2012 is taken as the first variable, and the number of other groups is taken as the second variable, which is summarized in Table 6. On the one hand, it shows that one of the main reasons for the insufficient economic imbalance among cities (autonomous prefectures) in Sichuan Province is the poor degree of industrial dependence; On the other hand, the innovation relationship between regions is divided and independent. From the analysis results of the selected highway traffic, the accessibility and convenience between regions are also the "bottleneck" affecting economic development. From the perspective of local correlation analysis, the trend of scientific research talents gathering in Chengdu or its surrounding areas is obvious, which is favorable for Chengdu to continue to maintain its innovation driven advantage, but for other regions, it will form a shortage of innovative talents, which is not conducive to the overall improvement of the economic development level and speed of the whole province.

Table 6. Local autocorrelation analysis of cities (autonomous autonomous prefectures) in 2012 


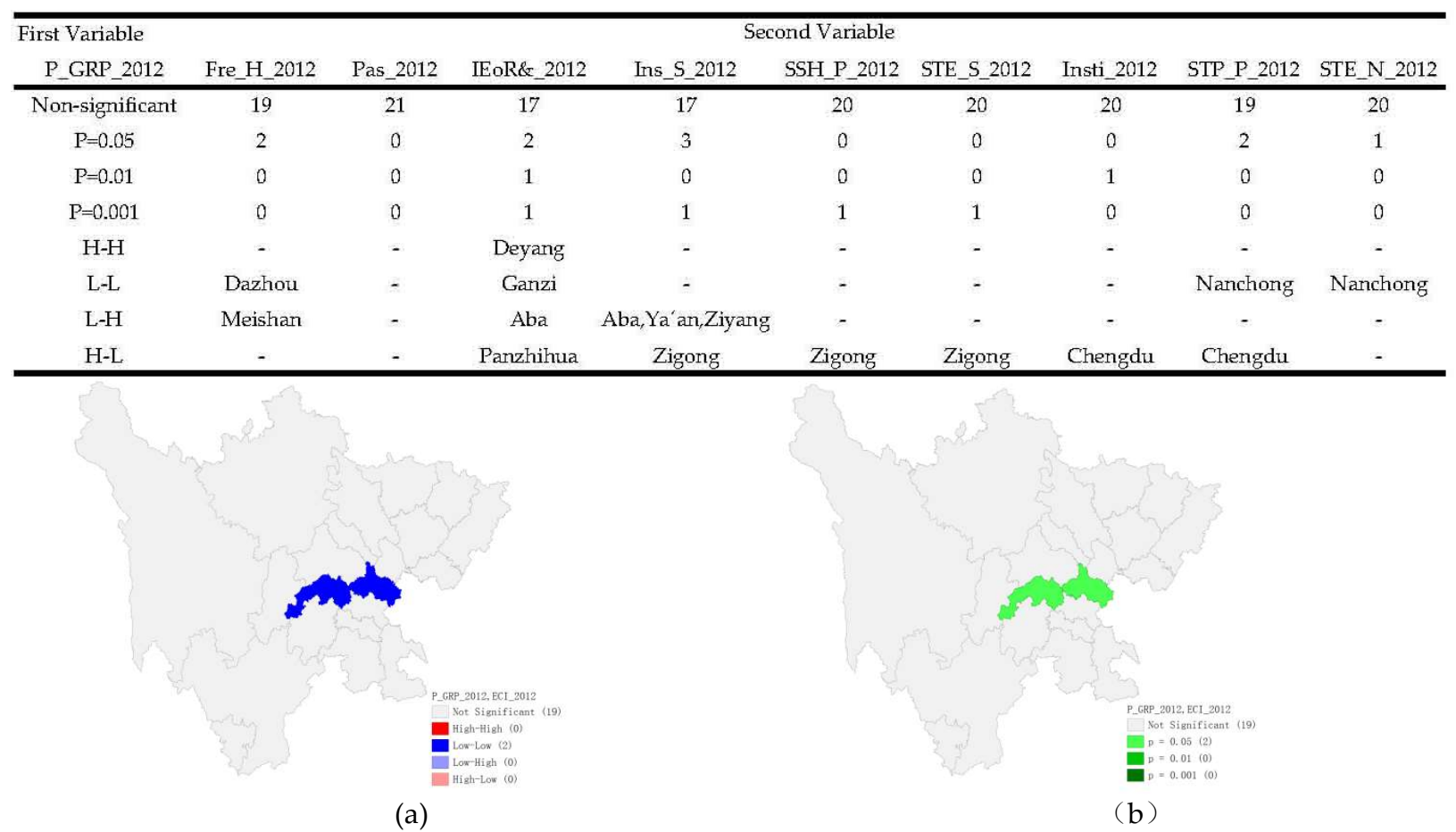

Figure 8. Local correlation of per capita GRP, per unit GRP and per unit energy consumption index, and: (a) LISA of per capita GRP and energy consumption per unit of GRP in 2012; (b) Significence of per capita GRP and energy consumption per unit of GRP in 2012.

Once again, the per capita GRP in 2018 is selected as the first variable, and the energy consumption index per unit GRP in 2018 is selected as the second variable to explore the local spatial correlation of cities (Autonomous prefectures). The results are shown in Figure 9. According to the bivariate Lisa significance map, among the 21 cities (autonomous prefectures), 15 cities (autonomous prefectures) are not significant, among which Ganzi, Mianyang, Deyang, Guang'an, Leshan and Panzhihua are significantly correlated ( $\mathrm{P}=$ 0.05), among which Leshan and Panzhihua are "High-High" clustering, Deyang and Mianyang are "High-Low" clustering, and Ganzi is "Low-High" clustering, Guang'an City presents "low low" clustering. From the perspective of local correlation, the correlation is also not high, but it shows a trend throughout the whole province.

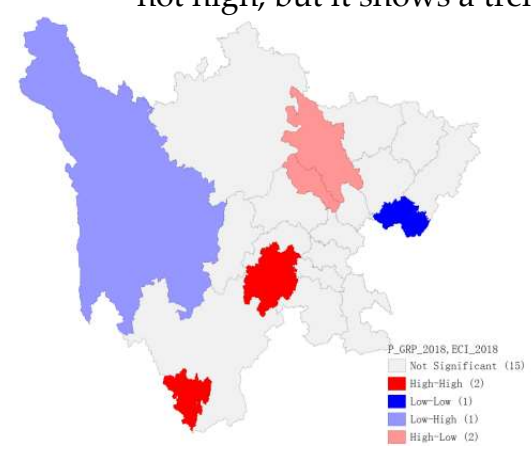

(a)

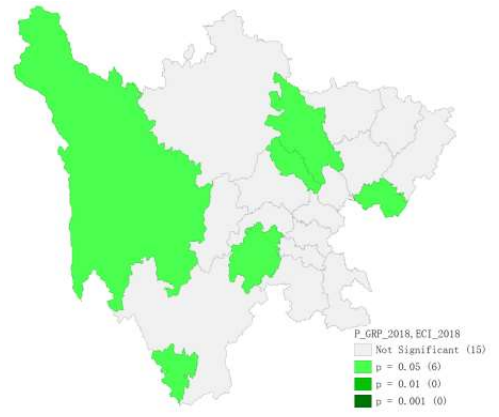

(b)

Figure 9. Local correlation of per capita GRP, per unit GRP and per unit energy consumption index, and: (a) LISA of per capita GRP and energy consumption per unit of GRP in 2018; (b) Significence of per capita GRP and energy consumption per unit of GRP in 2018.

Similarly, taking the per capita GRP in 2018 as the first variable and the number of other groups as the second variable, the local correlation analysis results are summarized in Table 7. In 2018, Deyang's capital and talent investment in scientific research activities 
showed a "High-High" clustering; In addition to the number of scientific research institutions in the field of natural science and technology, the number of scientific research activities in the field of Humanities and Social Sciences in Ya'an City presents a "Low-High" clustering, which is not conducive to the long-term healthy economic development of Ya'an City; Zigong City's scientific research activities in the field of Humanities and Social Sciences show a "high low" clustering, and the field of natural sciences is not significant, which will also cause the imbalance of regional economic development.

Table 7. Local autocorrelation analysis of cities (autonomous prefectures) in 2018

\begin{tabular}{|c|c|c|c|c|c|c|c|c|c|}
\hline \multirow{2}{*}{$\frac{\text { First Variable }}{\text { P_GRP_2018 }}$} & \multicolumn{9}{|c|}{ Second Variable } \\
\hline & Fre_H_2018 & Pas_2018 & IEoR\&_2018 & Ins_S_2018 & SSH_P_2018 & STE_S_2018 & In_NS_2018 & STP_P_2018 & STE_N_2018 \\
\hline Non-significant & 21 & 19 & 18 & 18 & 18 & 18 & 20 & 20 & 19 \\
\hline$P=0.05$ & - & 2 & 2 & 1 & 2 & 1 & 1 & 1 & 2 \\
\hline $\mathrm{P}=0.01$ & - & 0 & 1 & 1 & 0 & 1 & 0 & 0 & 0 \\
\hline $\mathrm{P}=0.001$ & - & 0 & 0 & 1 & 1 & 1 & 0 & 0 & 0 \\
\hline $\mathrm{H}-\mathrm{H}$ & - & - & Deyang & Deyang & Deyang & Deyang & Yáan & - & - \\
\hline L-L & - & Liangshan & Ganzi & - & - & - & - & Nanchong & Nanchong \\
\hline $\mathrm{L}-\mathrm{H}$ & - & Zigong & Aba & Ya'an & Yáan & Ya'an & - & - & Aba \\
\hline $\mathrm{H}-\mathrm{L}$ & - & - & - & Zigong & Zigong & Zigong & - & - & - \\
\hline
\end{tabular}

\section{Conclusion}

Based on the results of regional economic development as the dependent variable (the selected indicators are GRP and GRP per capita), this paper investigates the relationship between economic development and innovation drive in Sichuan Province and the spatial distribution characteristics of regional economy. The main conclusions are as follows:

In addition to Chengdu, the main driving forces of economic development in other areas of Sichuan Province are still factor driven and investment driven. The spatial correlation of economic development factors in Sichuan Province is not significant, and the industrial dependence between regions is low. This is the main reason for the unbalanced and inadequate economic development in Sichuan Province. Therefore, the cultivation and improvement of regional industrial dependence will help to eliminate the imbalance and insufficiency of economic development.

Accessibility and speed of transportation not only reflect the regional investment, but also the basic conditions of economic development. The traffic accessibility and capacity of Sichuan Province are difficult to adapt to the current economic development, and the contribution of highway traffic to the economy in this paper is not significant. Limited by the data of water transportation, railway (especially high-speed railway) and air transportation, it is difficult to obtain, but the construction of high-speed and efficient transportation network is also the main challenge for the better and faster economic development of Sichuan Province.

The role of innovation in the economic development of various cities (autonomous prefectures) in Sichuan Province varies greatly. Except Chengdu, the capital of the province, the impact of innovation is extremely significant, other regions are not obvious, and there is even a negative correlation in some regions, so the innovation in the province can not form an organic collaborative whole. Innovation drive is a systematic project, which puts forward high requirements for innovation environment, innovation input intensity, innovation direction, innovative talents and innovation collaboration. In particular, the competition of innovative talents is the key to determine whether Sichuan Province can achieve the goal of building an innovative province.

Based on the analysis of the role of relevant factor driven, investment driven and innovation driven in economic development of cities (autonomous prefectures) in Sichuan Province in 2012 and 2018, it is found that the three are interdependent, mutually restricting and promoting, not developing or abandoning step by step. 
In a word, the construction of innovation system engineering is the core work to eliminate the polarization and imbalance of regional economic development in Sichuan Province, and the realization of scientific and reasonable regional economic spatial layout is the starting point of industrial development.

Author Contributions: Conceptualization, H.W. and M.L.; methodology, H.W.; software, H.W.; data curation and collation, Z.E.; writing-original draft preparation, H.W.; writing-review and editing, H.W. and Z.E.; supervision, M.L.; project administration, H.W.; funding acquisition, H.W. and M.L. All authors have read and agreed to the published version of the manuscript.

Funding: This research was funded by Science \& Technology Department of Sichuan Province, project is Research on the scientific and technological innovation path of Implementing Rural Revitalization Strategy in deep poverty stricken areas of Sichuan Province, grant number is 2020JDR0171. This research was also funded by Ph.D. Research Start-up Fund of Xichang University, project is Research on innovation driven development model of Liangshan Yi Autonomous Prefecture, grant number is YBS202103.

Conflicts of Interest: The authors declare no conflict of interest. The funders had no role in the design of the study; in the collection, analyses, or interpretation of data; in the writing of the manuscript, or in the decision to publish the results.

\section{References}

1. Schumpeter J.A. The theory of economic development. Harvard University Press 1932, Volume, page range.

2. European Union. Oslo Manual 2018: Guidelines for Collecting, Reporting and Using Data on Innovation( 4th Edition). https://www.oecd.org/innovation/oslo-manual-2018-9789264304604-en.htm.

3. Yinxing.H. Economic analysis of industry university research collaborative innovation. Economic Science 2014, 36, 56-64.

4. Porter, M. E. The Competitive Advantage of Nations. New York: Free Press, 1990.

5. Yinxing.H. Several important concepts about innovation driven and innovative economy. Qunzhong 2011, 2011 (8) , 31-33.

6. Interpretation of the notice of the general office of Sichuan Provincial People's Government on printing and distributing the implementation plan of Sichuan innovative province construction. http://www.sc.gov.cn/10462/10464/13298/13301/2017/11/17/10438465.shtml.

7. Yuanpin.F.; Man X. Spatial distribution of innovation factors and its impact on regional innovation output: Based on esda-gwr analysis of China's provinces. Economic Geography 2012, 32, 8-14.

8. Rob K.; Nicholas J. T. Conducting research in human geography: Theory, Metyodology \& Practice. Pearson Prentice Hall 2006, pp. 245-267.

9. Din L.; Xiao-mei L.; Shen-lan W. Analysis on deepening and driving forces of spatial differences of county economy based on esda-gis- A case study of Lanzhou Xining urban agglomeration. Economic Geography 2013,33, pp. 31-36. 